Dhaka Univ. J. Biol. Sci. 24(2): 161-168, 2015 (July)

\title{
OCCURRENCE OF PROTOZOA AND SOIL TRANSMITTED HELMINTH (STH) IN HUMAN FECES USED AS MANURE IN AGRICULTURE
}

\author{
Tamanna Akter, Sharmin Musa and Hamida Khanum \\ Department of Zoology, University of Dhaka, Dhaka-1000, Bangladesh
}

Key words: Occurrence, Protozoa, Soil transmitted helminth, Infection and manure

\begin{abstract}
To assess the health risk association of soil contamination with parasite, a total number of 168 faecally contaminated night soil was studied. The presence of four protozoan parasites, viz. Cryptosporidium sp., Entamoeba histolytica, Giardia sp., Trichomonas hominis and eight different helminthes, viz. Diphyllobothrium latum, Hymenolepis sp., Taenia sp., Ascaris lumbricoides, Ancylostoma duodenale, Enterobius vermicularis, Strongyloides stercolaris and Trichuris trichiura were identified. Among the protozoans, Giardia sp. was the highest (46.43\%) and most abundant (339.87 \pm 17.01 cysts/g); among helminthes the prevalence of Ascaris lumbricoides was the highest $(80.95 \%)$ and Strongyloides stercoralis was mostly abundant (409.31 \pm 47.53 larvae/g). Highest percentage of mild infections was found in Giardia sp. (43.45), and lowest in Trichomonas hominis (8.33). Whereas, among helminthes, highest percentage (64.29), of mild infections was found in Ascaris lumbricoides and lowest (11.90) in Taenia. In case of protozoa, moderate infection found in Giardia sp. (2.98\%) and Entamoeba histolytica (3.57\%), but in case of helminth only Ascaris lumbricoides showed moderate infections (16.67\%).
\end{abstract}

\section{Introduction}

Parasitic infestation is one of the causes of anaemia ${ }^{(1,2)}$. Shah and Baig ${ }^{(3)}$ reported that anaemia significantly related with helminth infection. Actually parasitic infections may reduce competitive fitness(4,5) thus influence population cycles( ${ }^{(6)}$ and regulate host population abundance ${ }^{(7)}$. Often, parasitic infections tend to be over dispersed, to where many individual hosts have low parasite intensities and a few individuals have high intensities of parasites ${ }^{(5,8,9)}$. Thus, many animals may maintain low levels of infection whereas a few actually succumb to disease. The sanitary condition in rural communities of Bangladesh was unsatisfactory, more than $75 \%$ families have insanitary latrines which were mostly infected with helminthes ${ }^{(10)}$. Contaminated food and water, inadequate sanitation and poor personal hygiene may be the major sources of intestinal parasite infection.

Adult parasites and their eggs may inhabit soil; therefore, poor nutrition and sanitation may foster the spread of infections. From the hygienic point of view, any exposure to faeces constitutes a risk(11) and thus faeces should always be considered potentially to contain pathogens. Most pathogenic or potentially intestinal pathogenic 
microorganism enter a new host by ingestion or through the lungs or through the eye, when eyes are rubbed with contaminated fingers, ${ }^{(11)}$ while others may also enter through the skin or wounds.

Fecal wastes from domestic animals, wildlife and humans are applied to the soil surface and to varying extents are incorporated into the soil. These fecal wastes can also enter water systems by direct contamination of the water or through seepage or surface run off. Raw sewage is processed to varying degrees before it is distributed on soil or discharged into water systems. Failure to appropriately process human sewage probably poses the greatest threat to human health, however it is often impossible to identify sources of food and water contamination.

Actually using night soil solves environmental and sanitary problems systematically(12). It helps to return resources to the environment through the resource recovery process of the nutrient cycle and also build a bridge between sanitation and agriculture ${ }^{(13)}$. But parasites can contaminate crops through various routes, for example, via water contaminated by faeces that used for irrigation or spraying of crops. Intestinal parasites are producing detrimental effects on health of millions of people mainly children and adolescents in Bangladesh.(14) Several studies showed that intestinal parasitic infections are present all the time everywhere in Bangladesh. ${ }^{(15)}$ In Bangladesh, among the helminths and protozoan parasites, A. lumbricoides, A. duodenale, T. trichura, Enterobius vermicularis and Etaboeba histolytica, Giardia lamblia are common.(16)

In developing countries, excreta-related diseases are very common, and human faeces contain correspondingly high concentrations of excreted pathogens - the bacteria, viruses, protozoa, and helminths (worms) that cause gastro-intestinal infections in man. So the main objectives of this work were to estimate the actual risks to the public health that occur through night soil use in agriculture; to enumerate prevalence of protozoa and helminth; and to measure the single, double and multiple infections.

\section{Materials and Methods}

The present study was conducted by collecting 168 samples from selected areas in rural Tangail, Bangladesh and laboratory analysis was done in the Parasitology laboratory of Zoology, Dhaka University. The study period extends from February, 2013 to March, 2014. For analysis, firstly faecal sludge on the samples was dewatered on a drying bed. Dewatering was used to separate faecal sludges from on site sanitation. This process does not treat the sludge, it only separates solid from liquid part. Then, dewatered sludges were mixed at a aludge: solid organic material $(1: 3)$ volume ratio ${ }^{(17)}$. The active composting process lasted for one month and then collected for laboratory analysis and stored at a $4^{\circ} \mathrm{C}$ until analysis. This manure was used in growing vegetables and plants, such as, cauliflower (Brassica oleracea), cabbage (Brassica oleracea capitata), bottle gourd (Lagenaria siceraria), brinjal (Solanum melongena), snake gourd (Trichosanthes 
cucumerina), bitter gourd (Momordica chanantia), and mango (Mangifera indica), jackfruit (Artocarpus heterophyllus), orange (Citrus sinensis), wood apple (Aegle marmelos) etc.

Samples were collected in a small sterile, clean and leak proof plastic container or fresh transparent polythene bag. All the samples were preserved with most suitable and available preservative ( $10 \%$ formalin). After collection, samples were kept in a cool dry place and examination was carried in Parasitology Lab, Dhaka University. From each sample, at least two slide were examined separately through the processing and technique, and the results were recorded accordingly.

The formol-ether concentration technique ${ }^{(18)}$ was applied for the diagnosis of protozoa and soil-transmitted helminthes. The units for measuring the intensity of infection at the individual level are "eggs per gram of faeces" (EPG), for determining the number of parasite's eggs per gram of feces in order to estimate the worm burden material on the slides. Firstly, weight out 3 grams of feces and measure out $42 \mathrm{ml}$ of water and place it into a dish. Using a tongue depressor, push the 3 grams of feces through a sieve into the water, lift the sieve and hold over the dish. While stirring the water-feces mixture, take $0.15 \mathrm{ml}$ of the suspension and spread over 2 slides. Cover each slide with a long coverslip. Examine both slides for worm eggs, the total number of eggs counted $\times 100$ represents the number of eggs per gram of feces. The mathematics: $0.15 \mathrm{ml}$ is $1 / 300$ of $45 \mathrm{ml}$ (42 ml water and $3 \mathrm{gm}$ feces) so the number of eggs in $0.15 \mathrm{ml} \times 100$ is equal to $1 / 3$ of the total number of eggs in the original $3 \mathrm{~g}$ and thus equal to eggs per gram (EPG). This technique is known as stool's egg counting technique. The advantage of this technique is that it requires no specialized equipment and the disadvantage is the counting takes a long time because of the amount of extra (nonegg) material on the slides.

When the occurrence of the range of parasite number in the form of cyst or ova or larvae were from 300 to 599, from 600 to 1099, from 1100 to 1300/g of human feces in each sample infestation level would be marked positive and designated as mild, moderate and heavy, respectively. The level of infection cases were classified as mild, moderate and heavy infection according to $\mathrm{WHO}^{(19)}$ cut off values.

\section{Results and Discussion}

Twelve intestinal parasite species were identified from the human feces, these include four protozoans, viz. Cryptosporidium sp., Entamoeba histolytica, Giardia sp. and Trichomonas hominis; three cestodes, viz. Diphyllobothrium latum, Hymenolepis sp. and Taenia sp.; and five nematodes, viz. Ascaris lumbricoides, Ancylostoma duodenale, Enterobius vermicularis, Strongyloides stercoralis and Trichuris trichiura (Table 2).

The level of prevalence of helminth was mostly similar to the findings of Tu et al.(20), who reported $90 \%$ prevalence of helminths in their study population. Actually eggs of helminths including Ascaris spp., Trichuris spp. and hookworms need a period of time, 
outside the host body to develop and attain infective stage. Presence of these parasites in the environment can be a public health indicator ${ }^{(21)}$. High prevalence $(96.42 \%)$ of these helminths in the present study indicates higher contamination of soil samples (Table 1).

Table 1. Prevalence of intestinal parasites in the observed night soil samples collected from Tangail from February, 2013 to March, 2014.

\begin{tabular}{lllllllc}
\hline Parasites & $\begin{array}{c}\text { No. of } \\
\text { total } \\
\text { sample }\end{array}$ & $\begin{array}{c}\text { Positive } \\
\text { (Total) }\end{array}$ & $\begin{array}{c}\text { Prevalence } \\
(\%)\end{array}$ & $\begin{array}{c}\text { Positive } \\
(\text { only) }\end{array}$ & $\begin{array}{c}\text { Prevalence } \\
(\%)\end{array}$ & $\begin{array}{c}\text { No. of } \\
\text { protozoa and } \\
\text { helminth } \\
\text { parasite }\end{array}$ & $\begin{array}{c}\text { Preva- } \\
\text { lence } \\
(\%)\end{array}$ \\
\hline Protozoa & 168 & 128 & 76.19 & 06 & 3.57 & & 72.62 \\
Helminth & 168 & 162 & 96.42 & 40 & 23.80 & 122 & \\
& Cestode & 75 & 46.30 & 08 & 4.94 & & \\
& Nematod & 123 & 75.93 & 32 & 19.75 & & \\
\hline
\end{tabular}

Table 2. Prevalence, dominance, intensity, and CPG/EPG of intestinal parasites in observed samples.

\begin{tabular}{lccccc}
\hline Parasites & $\begin{array}{c}\text { No. of } \\
\text { contaminated } \\
\text { samples }\end{array}$ & Prevalence & $\begin{array}{c}\text { Dominance } \\
(\%)\end{array}$ & $\begin{array}{c}\text { Cyst/egg } \\
\text { per gram } \\
\text { (CPG/EPG) }\end{array}$ & $\begin{array}{c}\text { Intensity } \\
( \pm \text { SD })\end{array}$ \\
\hline Protozoa & & & & & \\
Trichomonas hominis & 14 & 8.33 & 10.93 & 306.43 & $306.43 \pm 6.16$ \\
Entamoeba histolytica & 76 & 45.24 & 59.38 & 274.75 & $274.75 \pm 6.44$ \\
Giardia sp. & 78 & 46.43 & 60.94 & 339.87 & $339.87 \pm 17.01$ \\
Cryptosporidium sp. & 22 & 13.09 & 17.19 & 314.54 & $314.54 \pm 10.63$ \\
Cestode & & & & & \\
Hymenolepis sp. & 50 & 29.76 & 30.86 & 343.60 & $343.60 \pm 40.11$ \\
Taenia sp. & 20 & 11.90 & 12.35 & 355.30 & $355.30 \pm 21.05$ \\
Diphyllobothrium latum & 62 & 36.90 & 38.27 & 307.60 & $307.60 \pm 6.30$ \\
Nematode & & & & & \\
Ascaris lumbricoides & 136 & 80.95 & 83.95 & 333.16 & $333.16 \pm 19.84$ \\
Trichuris trichiura & 34 & 20.24 & 20.99 & 311.65 & $311.65 \pm 4.01$ \\
Hookworm & 64 & 38.10 & 39.51 & 376.41 & $376.41 \pm 52.99$ \\
Strongyloides stercoralis & 58 & 34.52 & 35.80 & 409.31 & $409.31 \pm 47.53$ \\
Enterobius vermicularis & 26 & 15.48 & 16.05 & 316.08 & $316.08 \pm 64.26$ \\
\hline
\end{tabular}

Giardia sp. (46.43\%), Entamoeba histolytica (45.24\%), Ascaris lumbricoides (80.95\%), and Hookworm $(38.10 \%)$ were highly prevalent; other parasites were comparatively less frequent (Table 2). The prevalence of hookworm was $38.10 \%$ which showed close to the 
findings of Khanum et al.(22). They observed that the prevalence of hookworm infection was higher in Kutumbopur (30\%) than that of in Gazirchat (26.7\%). The prevalence of $T$. trichiura $(20.24 \%$ ) also revealed similarity (Table 2 ) to Khanum et al.(23), who carried out a study among the children in two slum areas in Dhaka city and reported the higher prevalence of T. trichiura (18.80\%) in Agargaoan than Mirpur slum area (16.17\%).

The highest percentage of mild infections was due to Giardia sp. (43.45\%), and lowest due to Trichomonas hominis (8.33\%). Whereas, among helminthes, highest percentage of mild infections was caused by Ascaris lumbricoides (64.29\%) and lowest by Taenia (11.90). In case of protozoa, moderate infection was due to Giardia sp. (2.98\%) and Entamoeba histolytica $(3.57 \%)$. But in case of helminth only Ascaris lumbricoides caused moderate infections (16.67\%) (Table 3).

Table 3. Prevalence of mild and moderate infections positive samples.

\begin{tabular}{lcccc}
\hline Parasites & $\begin{array}{c}\text { No. of mild } \\
\text { infection positive } \\
\text { samples }\end{array}$ & $\begin{array}{c}\text { Prevalence } \\
(\%)\end{array}$ & $\begin{array}{c}\text { No. of moderate } \\
\text { infection } \\
\text { samples }\end{array}$ & $\begin{array}{c}\text { Prevalence } \\
(\%)\end{array}$ \\
\hline Protozoa & 14 & 8.33 & & \\
Trichomonas hominis & 70 & 41.67 & 06 & 3.57 \\
Entamoeba histolytica & 73 & 43.45 & 05 & 2.98 \\
Giardia sp. & 22 & 13.10 & & \\
Cryptosporidium sp. & & & & \\
Cestode & 50 & 29.76 & & \\
Hymenolepis sp. & 20 & 11.90 & & \\
Taenia sp. & 62 & 36.90 & & \\
Diphyllobothrium latum & 108 & 64.29 & & \\
Nematode & 34 & 20.24 & & \\
Ascaris lumbricoides & 64 & 38.10 & & \\
Trichuris trichiura & 58 & 34.52 & & \\
Hookworm & 26 & 15.48 & & \\
Strongyloides stercoralis & & & & \\
Enterobius vermicularis & & & & \\
\hline
\end{tabular}

Willets ${ }^{(24)}$ reported $54.37 \%$ for hookworm infestation in over 4000 samples and Walker et al.(25) found $48.27 \%$ hookworm infestation in 58 persons at Mindoro. Hookworm infestation in both the findings was slight higher than the present observation which was $38.10 \%$ (Table 3 ). The defecation manner in open space by animal or human may be the possible source of intestinal parasites. Intestinal parasites found in these samples indicate faecal contamination of the soil. However, the lower prevalence (11.84\%) of Ascaris lumbricoides was observed by Reinthaler et al.(26) who conducted 
survey in South-west Nigeria, whereas present investigation revealed $80.95 \%$ prevalence of Ascaris lumbricoides. This might be due to different climate condition that persists in Nigeria. The potential risk of contracting helminthic ova and larvae through ingestion of unwashed, raw or uncooked fruits and vegetables obtained from farmlands.

Enhanced disease surveillance, epidemiological systems and techniques are needed to improve our current understanding of the significance of these organisms in primary production and throughout the food chains. None-the-less, the number of infections can be used to give an idea of the national scale of the effort required to control protozoa and soil transmitted helminthes (STHs). The economy of Bangladesh largely depends on agriculture; livestock and about $80 \%$ people of the country are directly or indirectly depend on agriculture ${ }^{(27)}$. Assessment of the degree of infection of parasite will help to recommend possible ways and means to control and prevention of protozoan and helminthic parasite and thus improve socio-economic conditions, sanitary practices which help to control the extent of parasitic infestation and anaemia. Furthermore, results of the study will allow the planners, professionals and researchers of the country to take appropriate preventive and remedial measures to control parasitic infestation and henceforth improve the extent of anaemia and overall nutritional status, health and wellbeing of population of the country. Poverty and poor hygiene were implicated as an important risk factor for intestinal parasitic infestations. Improving the sanitation level, creating awareness about health and hygiene and promotion of de-worming therapy program could reduce intestinal parasitic infestations.

\section{References}

1. Banu H, H Khanum and MA Hossain 2011. Parasitic infestation among the adolescent girls of Bangladesh. Proceedings of the 22nd National Congress on Parasitlogy (Oct. 30 - Nov. 1, 2010). Advance in Parasitology: A novel approach towards a disease freeworld. University of Kalyani, Kolkata, India. pp. 91-97.

2. Banu $\mathrm{H}$ and $\mathrm{H}$ Khanum 2013. Intestinal parasitosis with anaemia and nutritional status: adolescent girls of Bangladesh. LAMBERT Academic Publishing (LAP) GmbH and Co. KG Heinrich- Böcking-Str. 6-8 66121, Saarbrücken, Germany. pp. 308.

3. Shah BK and LA Baig 2005. Association of anaemia with parasitic infestation in pregnant Nepalese women: results from a hospital based study done in Eastern Nepal. J. Ayub Med. Coll. Abbottabad 17(1): 5-9.

4. Brassard P, ME Rau and MA Curtis 1982. Parasite induced susceptibility to predation diplostomiasis. Parasitology 85: 495-501.

5. Scott ME 1988. The impact of infection and disease on animal populations: implications for conservation biology. Conservation Biol. 2: 40-56.

6. Hudson PJ, AP Dobson and D Newborn 1998. Prevention of population cycles by parasite removal. Science 282: 2256-2258.

7. Anderson RM and RM May 1978. Regulation and stability of host-parasite population interactions: I. Regulatory processes. J. Animal Ecol. 47: 219-247. 
8. Müller-Graf CDM 1995. A coprological survey of intestinal parasites of wild lions (Panthera leo) in the Serengeti and the Nogorongoro Crater, Tanzania, East Africa. J. Parasitology 81: 812-814.

9. Junker K, L Debusho and J Boomker 2008. The helminth community of helmet guineafowls Numida meleagris (Linnaeus 1758), in the north of Limpopo Province, South Africa. Onderstepoort J. Veterinary Res. 75: 225-235.

10. Yusuf MM and AMZ Hussain 1990. Sanitation in rural communities in Bangladesh. Bulletine of the World Health Organization 68(5): 619-625.

11. Feachem RG, DJ Bradley, H Garelick and DD Mara 1983. Sanitation and Disease. Health aspects of Excreata and Wastewater Management. Wiley, Chichester.

12. Zhou L, RE Dickinson, Y Tian, J Fang, Q Li, RK Kaufmann, CJ Tucker and RB Myneni 2004. Evidence for a significant urbanization effect on climate in China. Proc. Natl. Acad. Sci. USA 101(26): 9540-9544.

13. Langergraber G and E Muellegger 2005. 'Ecological Sanitation - A way to solve global sanitation problems?' Environmental International 31(3): 433-44.

14. Karim MR, MA Rahman and MM Rahman 1998. Reflex: A guide to physiology and biochemistry. 8th ed. Shadow printing, Dhaka. pp. 62-108.

15. Shakur MS and MA Ehsan 1993. Intestinal parasites: A frequent association and contributing factor of loose motion in malnourished children. Bangladesh J. Child Health. 17(1): 10-13.

16. Banu $\mathrm{H}, \mathrm{J}$ d'Silva and $\mathrm{N}$ Islam 2003. Epidemiological factors and pinworm infection in children. Bangladesh J. Zool. 31(2): 243-246.

17. Strauss M, S Drescher, C Zurbruegg, A Montangero, C Olufunke and P Drechsel 2003. Cocomposting of Faecal Sludge and Municipal Organic Waste. Swiss Federal Institute of Aquatic Science (EAWAG), Department of Water and Sanitation in Developing Countries and International Water Management Institute.

18. Cheesbrough M 2004. District Laboratory Practice in Tropical Countries. Part I. Cambridge University Press. UK. pp. 454.

19. World Health Organization 1998. WHO/UNICEF iron deficiency: Indicators for assessment and strategies for prevention. WHO, Geneva.

20. Tu M, MM El-Zawahry and K Ohn 1970. Epidemiological features of intestinal parasitoses in Okopo village, Burma. Union of Burma J. Life Science 3: 247-267.

21. Saathoff E, A Olsen, JD Kvalsvig and PW Geissler 2002. Geophagy and its association with geohelminth infection in rural schoolchildren from northern KwaZulu- Natal, South Africa. Transactions of the Royal Society of Tropical Medicine and Hygiene 96: 485-490.

22. Khanum H, H Uddin and M Rahman 2005a. Hookworm infection and hygienic condition in the rural children of Bangladesh. Bangladesh J. Zool. 33(1): 75- 79.

23. Khanum H and MS Alam 2005b. Infection of Ascaris lumbricoides and Trichuris trichiura among the children of two slum area in Dhaka city. Bangladesh J. Zool. 33(1): 89-95.

24. Willets DG 1911. A statistical study of intestinal parasites in tobacco haciendas of the cagayan valley, Philippine Islands. Phil. Jour. Sci. 6(B): 77. 
25. Walker EL, AR Cuzman and I Concepcion 1914. Sanitary survey of the San Jose estate and adjacent properties of Mondoro Island, Philippine Islands, with especial reference to the epidemiology of Malaria. 6. The Disease Index. (A) Laboratory Examinations. Phil. Jour. Sci. 9(B): 167.

26. Reinthaler FF, F Mascher and W Klem 1988. A survey of gastrointestinal parasites in Ogun State, Southwest Nigeria. Ann. Trop. Med. Parasitol. 82: 181-184. False-negative results. J. Clin. Microbiol. 31(11): 3044-3045.

27. Bhuyan MA 1978. A survey of helminthes parasitizing the lives of Domesticated Ruminants in East Pakistan. M. S. Thesis-12. Department of Parasitology, Bangladesh Agricultural University, Mymensingh. pp. 150.

(Manuscript received on 22 March, 2015; revised on 10 June, 2015) 